\title{
Sarcopenia: burden and challenges for public health
}

\author{
Charlotte Beaudart ${ }^{1,2^{*}}$, René Rizzoli ${ }^{3}$, Olivier Bruyère ${ }^{1,2,5}$, Jean-Yves Reginster ${ }^{1,4}$ and Emmanuel Biver ${ }^{3}$
}

\begin{abstract}
Sarcopenia, operationally defined as the loss of muscle mass and muscle function, is a major health condition associated with ageing, and contributes to many components of public health at both the patient and the societal levels. Currently, no consensual definition of sarcopenia exists and therefore it is still a challenge to establish the actual prevalence of sarcopenia or to establish the direct and indirect impacts of sarcopenia on public health. Anyway, this geriatric syndrome represents a huge potential public health issue because of its multiple clinical and societal consequences. Moreover, all these aspects have an impact on healthcare costs both for the patient and the society. Therefore, the implementation of effective and broadly applicable preventive and therapeutic interventions has become a medical and societal challenge for the growing number of older persons affected by sarcopenia and its disabling complications.
\end{abstract}

Keywords: Sarcopenia, Public health, Epidemiology, Consequences, Diagnosis

\section{Background}

Thanks to social, health and technological progress, the proportion of older people in the age pyramid is increasing all over the world. According to the World Health Organisation, in 2050 there should be at least 2 milliards of people aged 65 years or older, compared to 600 million today. The life expectancy is also increasing and is estimated around 80 years in industrial countries [1]. The aging process is responsible of many changes in body composition including a loss of skeletal muscle mass. From the age of 25, there is a progressive decrease in the size and number of muscle fibres resulting in a loss of about $30 \%$ of muscle mass at the age of 80 [2]. Beyond some defined threshold, this age-related loss of muscle mass is characterized as abnormal. To characterize this phenomenon, the term "sarcopenia" was firstly introduced by Irwin Rosenberg [3]. The definition of sarcopenia was then enriched with scientific and technological advances and gradually evolved to incorporate the notions of decreased muscle mass [4], then of decreased muscle function (low muscle strength or low physical performance)

\footnotetext{
* Correspondence: c.beaudart@ulg.ac.be

'Department of Public Health, Epidemiology and Health Economics,

University of Liège, Avenue de I'Hôpital 3 - CHU B23, Liège 4000, Belgium

${ }^{2}$ Support Unit in Epidemiology and Biostatistics, University of Liège, Liège,

Belgium

Full list of author information is available at the end of the article
}

[5-11]. These definitions differ from each other in regards to muscle mass indicators (ratio of appendicular lean mass over height squared, ALM/ht ${ }^{2}$, or over body mass index, $\mathrm{ALM}_{\mathrm{BMI}}$ ), the cutpoints for slow gait speed and whether or not they include a measure of weakness (Table 1). However, there is actually no universal consensus for an operational definition of sarcopenia, which is an important issue for public health.

A wide range of techniques can be used to measure the different components of sarcopenia [12]. Three techniques can be used for the measurement of appendicular lean mass: body imaging techniques, bio impedance analysis and anthropometry measures. In research, the two gold standards are the computed tomography (CT-scan) and the magnetic resonance imaging (MRI). However, because of the high costs and the limited access to this kind of equipment, the European Working Group on Sarcopenia in Older People (EWGSOP) [8] recommends in clinical practice, first the use of either dual energy Xray absorptiometry (DXA) or, as a portable alternative to DXA, the bioelectrical impedance analysis (BIA). Despite their easy use in clinical practice, the anthropometric measures are not recommended for the diagnosis of sarcopenia because these measures are not validated in older people and are, therefore, vulnerable to error. Several techniques are also available for the measurement of 
Table 1 Proposed operational definitions of sarcopenia

\begin{tabular}{|c|c|c|c|c|c|}
\hline \multirow[t]{2}{*}{ Criteria } & & \multirow[t]{2}{*}{ Muscle mass } & \multicolumn{3}{|l|}{ Muscle function } \\
\hline & & & Muscle strength & & Physical performance \\
\hline Baumgartner criteria [4] & Sarcopenia & $\mathrm{ASM} / \mathrm{ht}^{2}>2 \mathrm{SD}$ below young healthy mean & $x$ & & x \\
\hline $\begin{array}{l}\text { European Society for Clinical Nutrition and } \\
\text { Metabolism Special Interest Groups (ESPEN-SIG) [7] }\end{array}$ & Sarcopenia & $\begin{array}{l}\text { Percentage of muscle mass } \geq 2 \text { SD below mean in } \\
\text { young adults of the same sex and ethnic background } \\
\text { (individuals aged } 18-39 \text { years in the NHANES III cohort) }\end{array}$ & $x$ & & $\begin{array}{l}\text { Gait speed: }<0.8 \mathrm{~m} / \mathrm{s} \text { or Reduced } \\
\text { performance in any functional test } \\
\text { used for comprehensive geriatric } \\
\text { assessment }\end{array}$ \\
\hline \multirow{3}{*}{$\begin{array}{l}\text { European Working Group on Sarcopenia in Older } \\
\text { People (EWGSOP) [8] }\end{array}$} & \multirow[t]{2}{*}{ Sarcopenia } & $\mathrm{ALM} / \mathrm{ht}^{2}$ & Grip strength & OR & \multirow[t]{3}{*}{ Gait speed: $<0.8 \mathrm{~m} / \mathrm{s}$} \\
\hline & & - Men: $\leq 7.23 \mathrm{~kg} / \mathrm{m}^{2}$ & - Men: <30 kg & & \\
\hline & $\begin{array}{l}\text { Severe } \\
\text { sarcopenia }\end{array}$ & - Women: $\leq 5.67 \mathrm{~kg} / \mathrm{m}^{2}$ & - Women: $<20$ kg & AND & \\
\hline \multirow{3}{*}{$\begin{array}{l}\text { International Working Group on Sarcopenia } \\
\text { (IWGS) [9] }\end{array}$} & \multirow[t]{3}{*}{ Sarcopenia } & $\mathrm{ALM} / \mathrm{ht} \mathrm{t}^{2}$ & \multirow[t]{3}{*}{$x$} & & \multirow[t]{3}{*}{ Gait speed: $<1.0 \mathrm{~m} / \mathrm{s}$} \\
\hline & & - Men: $\leq 7.23$ kg/m² & & & \\
\hline & & - Women: $\leq 5.67 \mathrm{~kg} / \mathrm{m}^{2}$ & & & \\
\hline $\begin{array}{l}\text { Society of Sarcopenia, Cachexia and Wasting } \\
\text { Disorders [10] }\end{array}$ & $\begin{array}{l}\text { Sarcopenia with } \\
\text { limited mobility }\end{array}$ & $\begin{array}{l}\text { ALM } / h^{2}{ }^{2}>\text { of } 2 \text { SD below the mean of healthy persons } \\
\text { aged } 20-30 \text { years of the same ethnic group }\end{array}$ & $x$ & & $\begin{array}{l}\text { Gait speed: } \leq 1.0 \mathrm{~m} / \mathrm{s} \text { or Walking } \\
\text { distance }<400 \mathrm{~m} \text { during a } 6 \text {-min walk }\end{array}$ \\
\hline \multirow[t]{3}{*}{ Foundation of NIH Sarcopenia Project [11] } & \multirow{2}{*}{$\begin{array}{l}\text { Weakness and } \\
\text { low lean mass }\end{array}$} & ALM & Grip strength & & \multirow[t]{2}{*}{$x$} \\
\hline & & - Men: $<0.789$ & - Men: <26 kg & & \\
\hline & $\begin{array}{l}\text { Slowness with } \\
\text { weakness and } \\
\text { low lean mass }\end{array}$ & - Women: $<0.512$ & - Women: $<16$ kg & AND & Gait speed: $\leq 0.8 \mathrm{~m} / \mathrm{s}$ \\
\hline
\end{tabular}

$\mathrm{ASM} / \mathrm{ht}^{2}=$ ratio of appendicular skeletal muscle mass over height squared; $\mathrm{ALM} / \mathrm{ht} \mathrm{t}^{2}=$ ratio of appendicular lean mass over height squared; $\mathrm{ALM} \mathrm{BMI}_{\mathrm{I}}=$ ratio of appendicular lean mass over body mass index; SD standard deviation. 
muscle strength. Three techniques could potentially be used for the diagnosis of sarcopenia: handgrip strength, knee flexion or knee extension strength and the measurement of peak expiratory flow. In clinical research, the handgrip strength is the most widespread method. Indeed, this method does not require any special equipment, has been documented as a good marker of physical performance among community-dwelling older people and is well correlated with leg strength [13,14]. Finally, the physical performance can be measured by the "short physical performance battery test (SPPB)", by the "usual gait speed" or by the "timed up and go test" or "stair climb power test". The EWGSOP [8] recommends the use of either the usual gait speed, measured on a 4-meter distance or the SPPB test [15] which is a composite measuring walk speed, balance and the ability to stand up 5 times from a chair. Different cut-offs have been developed by the EWGSOP for each variable and could be applied for the diagnosis of sarcopenia. Recently, the Foundation of NIH Sarcopenia Project proposed recommendations for cut-off points for weakness and low lean mass definitions aiming to provide an operational definition for sarcopenia. It was recommended to assess muscle strength by grip strength with cutpoints $<26 \mathrm{~kg}$ in men and $<16 \mathrm{~kg}$ in women, and low lean mass by appendicular lean mass adjusted to BMI, with respective cutpoints $<0.789 \mathrm{~kg} / \mathrm{m}^{2}$ and $<0.512 \mathrm{~kg} / \mathrm{m}^{2}[16]$.

Given the variability in the definitions of sarcopenia, it is still a challenge to establish the actual prevalence of sarcopenia according to age and gender and to assess the direct and indirect impacts of sarcopenia on public health. The aim of this review is to discuss, both broadly and specifically, the public health implication of sarcopenia and its association with objectives health-related outcomes such as falls, fractures, admission in nursing homes or mortality.

\section{Discussion}

\section{Epidemiology of sarcopenia}

Sarcopenia is very common in older people. Currently it is still a public health challenge to establish a prevalence of sarcopenia. Indeed, this estimated prevalence depends on the type of studied population. A large number of studies have assessed the prevalence of sarcopenia within a cohort of adult subjects and this estimated prevalence could range from $0.1 \%$ to $85.4 \%$ according to patients' characteristics [17-22]. Globally, a higher prevalence of sarcopenia is often observed in men, in elderly subjects, in subjects living in nursing home, in subjects having a low body mass index but also in subjects having a low educational level. The prevalence of sarcopenia seems also to differ according to ethnicity. Indeed, a higher prevalence of sarcopenia is observed in Asian people and a lower prevalence is observed in people with dark skin compared to Caucasian people. Recently, a systematic review [23] on the prevalence of sarcopenia has been published. It indicates that the prevalence of EWGSOP-defined sarcopenia is $1-29 \%$ for older adults living in community. The differences in prevalence seem attributable to the age of the population and the methods of assessment used but also to the cut-offs used for the diagnosis.

Prevalence of sarcopenia could also differ depending on the definitions used for the diagnosis of sarcopenia, as recently highlighted in the comparison of the FNIH criteria with the International Working Group and the European Working Group for Sarcopenia in Older Persons [11]. In 2013, Batsis et al. [24] compared eight definitions of sarcopenia and found a prevalence ranging from $4.4 \%$ to $94 \%$ across definitions. In 2013, Bijlsma et al. found that the prevalence of sarcopenia with different diagnostic criteria ranged from $0 \%$ to $20.8 \%$ in the lowest age category (below 60 years), from $0 \%$ to $31.2 \%$ in the middle (60 to 69 years) and from $0 \%$ to $45.2 \%$ in the highest (above 70 years) [25]. As expected, studies using muscle mass as single criterion of diagnosis revealed a higher prevalence of sarcopenia than studies based on the EWGSOP consensus algorithm. The choice of cut-off limits applied could also influence the prevalence of sarcopenia. This is confirmed in a study (performed in our Department, in press) showing that the prevalence of sarcopenia can vary from $9.25 \%$ to $18 \%$ depending on the cut-offs used. This same study also shows the importance of the diagnostic tool chosen for the measurement of muscle mass, muscle strength and physical performance. Depending on the tool used, the prevalence of sarcopenia can range from $8.4 \%$ to $27.6 \%$.

Sarcopenia is also often related to multiple pathologies and comorbidities which can also compromise the measurement of its prevalence. Some authors are actually interested in sarcopenia in combination with another health issue, like osteoporosis, osteopenia, obesity, type II diabetes mellitus, breast cancer, etc. The prevalence of sarcopenia is systematically higher in subjects presenting another health condition than in healthy subjects. Sarcopenia could be, in this case, considered as one consequence of this health problem.

This confused state and the current impossibility of establishing a clear prevalence of sarcopenia makes comparisons between studies difficult and thus represents an important public health issue. Moreover, the various values for the prevalence of sarcopenia found across studies are probably associated with different characteristics of sarcopenic subjects which could compromise the implementation of pertinent therapeutic strategies in the field of sarcopenia.

\section{Consequences of sarcopenia: Indirect impact on public health}

Many consequences of sarcopenia are prognostic indicators of public health burden, such as the development of 
physical disability, nursing home admission, depression, hospitalization, and even mortality [26]. In particular, sarcopenia is associated with poor physical performance, functional decline and physical disability [22,26]. Sarcopenia predicts loss of independence for daily life activities in elderly men and women $[27,28]$, and also affects gait speed or regularity. Leg lean mass has been identified as an independent predictor of the level of mobility impairment assessed by the SPPB test [29]. Ability to walk is an obvious determinant of subsequent disability, mortality, and health care costs [30]. Sarcopenia is also associated with falls, a well known issue regarding the risk of fracture and disabilities (odds ratio for fall in the sarcopenia group relative to the normal group: 4.42 (95\% CI 2.08-9.39) in men and 2.34 (95\% CI 1.39-3.94) in women) [31].

Sarcopenia is also associated with many comorbidities which have a major impact on public health. As occurring concomitantly with age-related bone loss, sarcopenia coexists with osteoporosis and may increase fracture risk, potentially directly via crosstalk between muscle and bone tissues [32,33] and indirectly via increase of risk of falling [34,35]. Most of endocrine diseases (diabetes, hypogonadism, hypercortisolism...) as well as obesity, or chronic kidney disease [34], are associated with sarcopenia independently of age-related muscle loss, which may be an underlying mechanism by which chronic diseases cause physical disability [36].

In this context, sarcopenia is also associated with greater risk of hospitalization [37] and is highly prevalent among older adults admitted to acute care wards [38] or in nursing homes [39]. Sarcopenia is also a predictor of bad outcomes in patients who undergo major general or vascular surgery [40] or with serious illness, such as in transplantation or cancer outcome [41,42]. All these health-related consequences of sarcopenia are supposed to alter quality of life in these patients [43].

Importantly, several studies indicate that sarcopenia and indicators of alterations of muscle strength (such as grip strength, walking speed, chair rises, or standing balance) predict future mortality in middle-aged and older adults $[21,44]$. Sarcopenia is also associated with shortand long-term mortality in hospitalized patients [38], or in nursing home elderly residents [45].

Taken together, these data highlight how sarcopenia may impact various public health components, at the patient level with higher rate of disabilities, loss of independence, bad comorbidities outcome, institutionalization or mortality, but also at the societal level, contributing to major healthcare and dependence costs in disabled sarcopenic elderly (Figure 1). However, none of the proposed operational definitions of sarcopenia demonstrated its superiority to be predictive of these health-related "hard" outcomes, such as fractures, falls, admission in nursing homes, or mortality. Future researches are clearly needed in this field to clarify which operational definition of sarcopenia should be integrated in clinical practice to diagnose and target sarcopenia and its impact on public health.

\section{Public health costs of sarcopenia}

Disability is associated with an increased risk of hospitalization and nursing home placement, increased home healthcare and, obviously, health care expenditure. Given the effect of sarcopenia on disability, public health costs of sarcopenia are expected to be high. Currently, economic data on sarcopenia are very poor. Only one study has currently reported the healthcare costs of sarcopenia in the United States [46]. Those estimates have taken into consideration the direct costs of sarcopenia which raised, in 2000, to $\$ 18.5$ billion, $\$ 10.8$ billion in men and $\$ 7.7$ billion in women. These costs are represented by hospitalization, nursing home admissions and home healthcare expenditure. In 2000, this amount represented about $1.5 \%$ of total health expenditure in the United States. It must be added that, in addition to disability, sarcopenia is associated with multiple comorbidities and may also have effect on osteoporosis [47], obesity [48] and type II diabetes mellitus [49]. Whith these comorbidities associated healthcare costs taken into account, the economic burden of sarcopenia may probably be even more important than reported in the study of Janssen [46]. This study is currently unique and, until now, no reliable economic assessment of sarcopenia has been performed in Europe.

Despite this lack of other economical assessment, several studies have however looked at the relationship between sarcopenia and different area of expenditure such as hospitalization or nursing home admission. In the United kingdom, one study has shown that, in comparison with patients without sarcopenia, those diagnosed with sarcopenia presented a mean length stay in hospital significantly higher (mean of $13.4 \pm 8.8$ days for sarcopenic subjects versus $9.4 \pm 7$ days for non-sarcopenic subjects; $\mathrm{p}=0.003$ ) [50]. The association between sarcopenia and hospitalization was examined in another study [37] showing a significant association between low muscle density (RR 1.5, 95\% CI 1.2-1.7) and grip strength (RR 1.5, 95\% CI 1.3-1.8) with hospitalization. Lean mass was however not associated with risk of hospitalization.

Although some studies have shown a higher risk of institutionalization among frail people [51-53], regarding sarcopenia specifically, no study has currently assessed the relationship between sarcopenia and nursing home admissions [54].

Sarcopenia is also associated with other healthcare costs area such as loss of productivity, reduced quality of live and loss of autonomy but also with psychological 


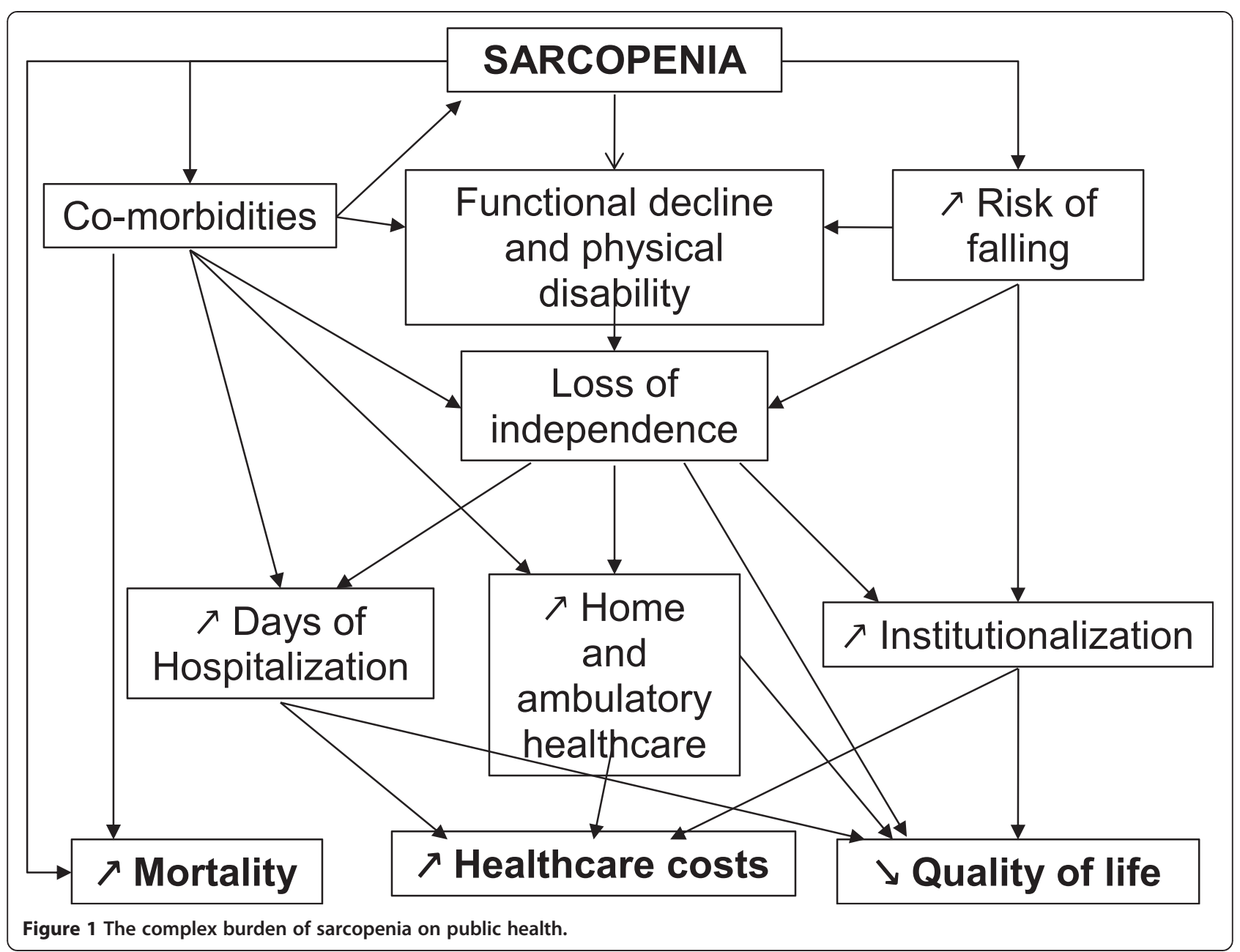

problems. However, these indirect costs of sarcopenia have never been quantified, neither in the US, nor in Europe.

In their assessment of healthcare costs of sarcopenia in the United States, Janssen et al. [46] also examined the effect that reduced prevalence of sarcopenia would have on healthcare expenditure, through for example pharmacological treatment, public health campaigns, physical activity intervention,. They found that a $10 \%$ reduction in the prevalence of sarcopenia would result in saving \$1.1 per year in the US. In a public health context, this potential economic saving is important. In comparison with osteoporotic fractures, for which the economic costs are similar [55] and for which numerous public health campaigns are organized aiming at reducing their occurrence, it is startling to note that, for sarcopenia, no public health campaigns are directly aimed at reducing the prevalence of this important geriatric syndrome. Because the number of older people is increasing all over the world, health policy decision-makers should consider some money investment in sarcopenia prevention and treatment to ensure important future savings.
Targeting sarcopenia: potential impact on public health Obviously there is currently no consensual operational definition of sarcopenia. This age-related condition has numerous consequences in public health, illustrated with relevant hard clinical outcomes such as falls, fractures, hospitalisations, institutionalizations, mortality. These consequences directly induce high personal, social and health care systems costs, which will most certainly increase steadily with population ageing. The implementation of effective and broadly applicable preventive interventions has become a medical and societal challenge for the growing number of older persons affected by sarcopenia and its disabling complications. Identifying and targeting the determinants of sarcopenia is a necessary first step to limit its impact on public health (Figure 1). In addition to the identification of the determinants of skeletal muscle loss, research strategies will have to include a lifecourse approach focused on factors associated with peak muscle mass and strength, such as birth weight [56] and early nutrition [57]. Nutritional interventions may influence sarcopenia, in particular diets rich in proteins and antioxidant 
nutrients, as well as vitamin D or omega-3 fatty acids supplements. Various exercise-related interventions (resistance exercise training, gait, balance, coordination and functional exercises) have been tested, targeting muscle strength, physical function, the risk of falls and balance in older people [58]. Potent pharmaceutical therapies have been proposed, such as hormone therapies (growth hormone, testosterone, selective androgen receptor modulator dehydroepiandrosterone, estrogen), angiotensin converting enzyme inhibitors, ghrelin agonists, but with up to now, little convincing effects or with presenting adverse side effects [58]. One of the most promising approaches may be the inhibition of myostatin, a regulator of muscle development and growth $[59,60]$. It is likely that combining lifestyle, nutritional, pharmacological and physical interventions is the most promising strategy. Clinical trials are currently conducted in this direction, such as the DoHealth study, which combines vitamin D, omega-3 fatty acids and physical exercise for the prevention of diseases at older age (ClinicalTrials.gov Identifier: NCT01745263). The costbenefit ratio of these interventions will have to be assessed in health economic models based on health care utilization and incidence of chronic diseases. However, a gap persists regarding assessment of specific health conditions related to sarcopenia, as fracture has become the relevant outcome to evaluate interventions targeting osteoporosis. Validation of specific, objective and reproducible outcomes or tools is a necessary step before considering the development of interventions targeting sarcopenia and likely to be recognized both by the scientific and medical community and regulatory agencies.

\section{Conclusion}

Sarcopenia has become a major health condition associated with ageing, and contributes to many components of public health at both the patient and the societal levels. It interferes with the incidence and prognosis of many comorbidities, and obviously increases health care utilization. It is a determinant of loss of independence, leading to institutionalizations or prolonged hospitalizations. All these aspects increase healthcare costs for the society, and affect quality of life and mortality of sarcopenic patients. With the improvement of life expectancy and the consensual previsions of marked increase of the proportion of older people, it is urgent to consider the economic and societal burden of sarcopenia, and to implement interventions to prevent and treat sarcopenia in the ageing population.

\footnotetext{
Abbreviations

ALM: Appendicular lean mass; MRI: Magnetic resonance imaging; EWGSOP: European working group on sarcopenia in older people; DXA: Dual energy X-ray absorptiometry; BIA: Bioelectrical impedance analysis; SPPB: Short physical performance battery.
}

\section{Competing interests}

The authors declare that they have no competing interests.

\section{Authors' contribution}

$O B$, JYR and RR conceived the study. CB and EB drafted the manuscript and $\mathrm{OB}$ helped to draft the manuscript. All authors read and approved the final manuscript.

\section{Author details}

'Department of Public Health, Epidemiology and Health Economics, University of Liège, Avenue de l'Hôpital 3 - CHU B23, Liège 4000, Belgium. ${ }^{2}$ Support Unit in Epidemiology and Biostatistics, University of Liège, Liège, Belgium. ${ }^{3}$ Division of Bone Diseases, Geneva University Hospitals and Faculty of Medicine, Rue Gabrielle Perret-Gentil 4, Geneva 14 CH-1211, Switzerland. ${ }^{4}$ Bone, Cartilage and Muscle Metabolism Unit and Chair of the Department of Public Health Sciences, CHU of Liège, Quai Godefroid Kurth 45, Liège 4000, Belgium. ${ }^{5}$ Department of Motricity Sciences, University of Liège, Liège, Belgium.

Received: 28 July 2014 Accepted: 15 October 2014

Published: 18 December 2014

\section{References}

1. Centers for Disease Control and Prevention (CDC): Trends in aging - United States and worldwide. MMWR Morb Mortal Wkly Rep 2003, 52:101-104. 106.

2. Lexell J, Taylor CC, Sjostrom M: What is the cause of the ageing atrophy? Total number, size and proportion of different fiber types studied in whole vastus lateralis muscle from 15- to 83-year-old men. J Neurol Sci 1988, 84(2-3):275-294.

3. Rosenberg: Summary comments. Am J Clin Nutr 1989, 50:1231-1233.

4. Baumgartner RN, Koehler KM, Gallagher D, Romero L, Heymsfield SB, Ross RR, Garry PJ, Lindeman RD: Epidemiology of sarcopenia among the elderly in New Mexico. Am J Epidemiol 1998, 147(8):755-763.

5. Newman AB, Kupelian V, Visser M, Simonsick E, Goodpaster B, Nevitt M, Kritchevsky SB, Tylavsky FA, Rubin SM, Harris TB: Sarcopenia: alternative definitions and associations with lower extremity function. J Am Geriatr Soc 2003, 51(11):1602-1609.

6. Cooper C, Dere W, Evans W, Kanis JA, Rizzoli R, Sayer AA, Sieber CC, Kaufman JM, Abellan Van Kan G, Boonen S, Adachi J, Mitlak B, Tsouderos Y, Rolland Y, Reginster JY: Frailty and sarcopenia: definitions and outcome parameters. Osteoporos Int 2012, 23(7):1839-1848.

7. Muscaritoli M, Anker SD, Argiles J, Aversa Z, Bauer JM, Biolo G, Boirie Y, Bosaeus I, Cederholm T, Costelli P, Fearon KC, Laviano A, Maggio M, Rossi Fanelli F, Schneider SM, Schols A, Sieber CC: Consensus definition of sarcopenia, cachexia and pre-cachexia: joint document elaborated by Special Interest Groups (SIG) "cachexia-anorexia in chronic wasting diseases" and "nutrition in geriatrics". Clin Nutr 2010, 29(2):154-159.

8. Cruz-Jentoft AJ, Baeyens JP, Bauer JM, Boirie Y, Cederholm T, Landi F, Martin FC, Michel JP, Rolland Y, Schneider SM, Topinkova E, Vandewoude M, Zamboni M: Sarcopenia: European consensus on definition and diagnosis: report of the European working group on sarcopenia in older people. Age Ageing 2010, 39(4):412-423.

9. Fielding RA, Vellas B, Evans WJ, Bhasin S, Morley JE, Newman AB, Abellan Van Kan G, Andrieu S, Bauer J, Breuille D, Cederholm T, Chandler J, De Meynard C, Donini L, Harris T, Kannt A, Keime Guibert F, Onder G, Papanicolaou D, Rolland Y, Rooks D, Sieber C, Souhami E, Verlaan S, Zamboni M: Sarcopenia: an undiagnosed condition in older adults. Current consensus definition: prevalence, etiology, and consequences. International working group on sarcopenia. J Am Med Dir Assoc 2011, 12(4):249-256.

10. Morley JE, Abbatecola AM, Argiles JM, Baracos V, Bauer J, Bhasin S, Cederholm T, Coats AJ, Cummings SR, Evans WJ, Fearon K, Ferrucci L, Fielding RA, Guralnik JM, Harris TB, Inui A, Kalantar-Zadeh K, Kirwan BA, Mantovani G, Muscaritoli M, Newman AB, Rossi-Fanelli F, Rosano GM, Roubenoff R, Schambelan M, Sokol GH, Storer TW, Vellas B, von Haehling S, Yeh SS, et al: Sarcopenia with limited mobility: an international consensus. J Am Med Dir Assoc 2011, 12(6):403-409.

11. Dam TT, Peters KW, Fragala M, Cawthon PM, Harris TB, McLean R, Shardell M, Alley DE, Kenny A, Ferrucci L, Guralnik J, Kiel DP, Kritchevsky S, Vassileva MT, Studenski S: An evidence-based comparison of operational criteria for the presence of sarcopenia. J Gerontol A Biol Sci Med Sci 2014, 69(5):584-590. 
12. Cooper $C$, Fielding $R$, Visser $M$, Van Loon $L$, Rolland $Y$, Orwoll $E$, Reid $K$, Boonen S, Dere W, Epstein S, Mitlak B, Tsouderos Y, Sayer AA, Rizzoli R, Reginster JY, Kanis JA: Tools in the assessment of sarcopenia. Calcif Tissue Int 2013, 93(3):201-210.

13. Stevens PJ, Syddall HE, Patel HP, Martin HJ, Cooper C, Aihie Sayer A: Is grip strength a good marker of physical performance among community-dwelling older people? J Nutr Health Aging 2012, 16(9):769-774

14. Roberts HC, Denison HJ, Martin HJ, Patel HP, Syddall H, Cooper C, Sayer AA: A review of the measurement of grip strength in clinical and epidemiological studies: towards a standardised approach. Age Ageing 2011, 40(4):423-429.

15. Guralnik JM, Simonsick EM, Ferrucci L, Glynn RJ, Berkman LF, Blazer DG, Scherr PA, Wallace RB: A short physical performance battery assessing lower extremity function: association with self-reported disability and prediction of mortality and nursing home admission. J Gerontol 1994, 49(2):M85-M94.

16. Studenski SA, Peters KW, Alley DE, Cawthon PM, McLean RR, Harris TB, Ferrucci L, Guralnik JM, Fragala MS, Kenny AM, Kiel DP, Kritchevsky SB, Shardell MD, Dam T, Vassileva MT: The FNIH sarcopenia project: rationale, study description, conference recommendations, and final estimates. J Gerontol A Biol Sci Med Sci 2014, 69(5):547-558.

17. Patel HP, Syddall HE, Jameson $K$, Robinson S, Denison $H$, Roberts $H C$, Edwards M, Dennison E, Cooper C, Aihie Sayer A: Prevalence of sarcopenia in community-dwelling older people in the UK using the European working group on sarcopenia in older people (EWGSOP) definition: findings from the Hertfordshire cohort study (HCS). Age Ageing 2013, 42(3):378-384.

18. Legrand D, Vaes B, Mathei C, Swine C, Degryse JM: The prevalence of sarcopenia in very old individuals according to the European consensus definition: insights from the BELFRAIL study. Age Ageing 2013, 42(6):727-734

19. Coin A, Sarti S, Ruggiero E, Giannini S, Pedrazzoni M, Minisola S, Rossini M, Del Puente A, Inelmen EM, Manzato E, Sergi G: Prevalence of sarcopenia based on different diagnostic criteria using DEXA and appendicular skeletal muscle mass reference values in an Italian population aged 20 to 80. Am Med Dir Assoc 2013, 14(7):507-512.

20. Volpato S, Bianchi L, Cherubini A, Landi F, Maggio M, Savino E, Bandinelli S, Ceda GP, Guralnik JM, Zuliani G, Ferrucci L: Prevalence and clinical correlates of sarcopenia in community-dwelling older people: application of the EWGSOP definition and diagnostic algorithm. J Gerontol A Biol Sci Med Sci 2014, 69(4):438-446.

21. Landi F, Cruz-Jentoft AJ, Liperoti R, Russo A, Giovannini S, Tosato M, Capoluongo E, Bernabei R, Onder G: Sarcopenia and mortality risk in frail older persons aged 80 years and older: results from ilSIRENTE study. Age Ageing 2013, 42(2):203-209.

22. Tanimoto $Y$, Watanabe $M$, Sun W, Sugiura $Y$, Tsuda $Y$, Kimura M, Hayashida I, Kusabiraki T, Kono K: Association between sarcopenia and higher-level functional capacity in daily living in community-dwelling elderly subjects in Japan. Arch Gerontol Geriatr 2012, 55(2):e9-e13.

23. Cruz-Jentoft AJ, Landi F, Schneider SM, Zuniga C, Arai H, Boirie Y, Chen LK, Fielding RA, Martin FC, Michel JP, Sieber C, Stout JR, Studenski SA, Vellas B, Woo J, Zamboni M, Cederholm T: Prevalence of and interventions for sarcopenia in ageing adults: a systematic review. Report of the international sarcopenia initiative (EWGSOP and IWGS). Age Ageing 2014, 0:1-2

24. Batsis JA, Barre LK, Mackenzie TA, Pratt SI, Lopez-Jimenez F, Bartels SJ: Variation in the prevalence of sarcopenia and sarcopenic obesity in older adults associated with different research definitions: dual-energy X-ray absorptiometry data from the national health and nutrition examination survey 1999-2004. J Am Geriatr Soc 2013, 61(6):974-980.

25. Bijlsma AY, Meskers CG, Ling CH, Narici M, Kurrle SE, Cameron ID, Westendorp RG, Maier AB: Defining sarcopenia: the impact of different diagnostic criteria on the prevalence of sarcopenia in a large middle aged cohort. Age (Dordr) 2013, 35(3):871-881.

26. Guralnik JM, Ferrucci L, Pieper CF, Leveille SG, Markides KS, Ostir GV, Studenski S, Berkman LF, Wallace RB: Lower extremity function and subsequent disability: consistency across studies, predictive models, and value of gait speed alone compared with the short physical performance battery. J Gerontol A Biol Sci Med Sci 2000, 55(4):M221-M231.

27. Tanimoto $Y$, Watanabe M, Sun W, Tanimoto K, Shishikura K, Sugiura Y, Kusabiraki T, Kono K: Association of sarcopenia with functional decline in community-dwelling elderly subjects in Japan. Geriatr Gerontol Int 2013, 13(4):958-963.

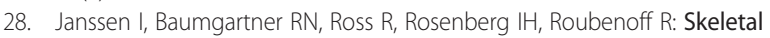
muscle cutpoints associated with elevated physical disability risk in older men and women. Am J Epidemiol 2004, 159(4):413-421.

29. Reid KF, Naumova EN, Carabello RJ, Phillips EM, Fielding RA: Lower extremity muscle mass predicts functional performance in mobility-limited elders. J Nutr Health Aging 2008, 12(7):493-498.

30. Hardy SE, Kang Y, Studenski SA, Degenholtz HB: Ability to walk 1/4 mile predicts subsequent disability, mortality, and health care costs. $J$ Gen Intern Med 2011, 26(2):130-135.

31. Tanimoto Y, Watanabe M, Sun W, Sugiura Y, Hayashida I, Kusabiraki T, Tamaki J: Sarcopenia and falls in community-dwelling elderly subjects in Japan: defining sarcopenia according to criteria of the European working group on sarcopenia in older people. Arch Gerontol Geriatr 2014, 59(2):295-299.

32. Brotto M, Johnson ML: Endocrine crosstalk between muscle and bone. Curr Osteoporos Rep 2014, 12(2):135-141.

33. Cianferotti L, Brandi ML: Muscle-bone interactions: basic and clinical aspects. Endocrine 2014, 45(2):165-177.

34. Kim JE, Lee YH, Huh JH, Kang DR, Rhee Y, Lim SK: Early-stage chronic kidney disease, insulin resistance, and osteoporosis as risk factors of sarcopenia in aged population: The Fourth Korea national health and nutrition examination survey (KNHANES IV), 2008-2009. Osteoporos Int 2014, 2014:2014

35. DiGirolamo DJ, Kiel DP, Esser KA: Bone and skeletal muscle: neighbors with close ties. J Bone Miner Res 2013, 28(7):1509-1518.

36. Kalyani RR, Corriere M, Ferrucci L: Age-related and disease-related muscle loss: the effect of diabetes, obesity, and other diseases. Lancet Diab Endocrinol 2014, 2(10):819-829.

37. Cawthon PM, Fox KM, Gandra SR, Delmonico MJ, Chiou CF, Anthony MS, Sewall A, Goodpaster B, Satterfield S, Cummings SR, Harris TB: Do muscle mass, muscle density, strength, and physical function similarly influence risk of hospitalization in older adults? J Am Geriatr Soc 2009, 57(8):1411-1419.

38. Vetrano DL, Landi F, Volpato S, Corsonello A, Meloni E, Bernabei R, Onder G: Association of sarcopenia with short- and long-term mortality in older adults admitted to acute care wards: results from the CRIME study. J Gerontol A Biol Sci Med Sci 2014, 69(9):1154-1161.

39. Landi F, Liperoti R, Fusco D, Mastropaolo S, Quattrociocchi D, Proia A Russo A, Bernabei R, Onder G: Prevalence and risk factors of sarcopenia among nursing home older residents. J Gerontol A Biol Sci Med Sci 2012 67(1):48-55.

40. Sheetz KH, Waits SA, Terjimanian MN, Sullivan J, Campbell DA, Wang SC, Englesbe MJ: Cost of major surgery in the sarcopenic patient. J Am Coll Surg 2013, 217(5):813-818.

41. Englesbe MJ, Patel SP, He K, Lynch RJ, Schaubel DE, Harbaugh C, Holcombe SA, Wang SC, Segev DL, Sonnenday CJ: Sarcopenia and mortality after liver transplantation. J Am Coll Surg 2010, 211(2):271-278.

42. Tan BH, Birdsell LA, Martin L, Baracos VE, Fearon KC: Sarcopenia in an overweight or obese patient is an adverse prognostic factor in pancreatic cancer. Clin Cancer Res 2009, 15(22):6973-6979.

43. Rizzoli R, Reginster JY, Arnal JF, Bautmans I, Beaudart C, Bischoff-Ferrari $H_{1}$ Biver E, Boonen S, Brandi ML, Chines A, Cooper C, Epstein S, Fielding RA, Goodpaster B, Kanis JA, Kaufman JM, Laslop A, Malafarina V, Mañas LR, Mitlak BH, Oreffo RO, Petermans J, Reid K, Rolland Y, Sayer AA, Tsouderos Y, Visser M, Bruyère O: Quality of life in sarcopenia and frailty. Calcif Tissue Int 2013, 93(2):101-120.

44. Cooper R, Kuh D, Hardy R: Objectively measured physical capability levels and mortality: systematic review and meta-analysis. BMJ 2010, 341:C4467.

45. Kimyagarov S, Klid R, Levenkrohn S, Fleissig Y, Kopel B, Arad M, Adunsky A: Body mass index (BMI), body composition and mortality of nursing home elderly residents. Arch Gerontol Geriatr 2010, 51(2):227-230.

46. Janssen I, Shepard DS, Katzmarzyk PT, Roubenoff R: The healthcare costs of sarcopenia in the United States. J Am Geriatr Soc 2004, 52(1):80-85.

47. Gillette-Guyonnet S, Nourhashemi F, Lauque S, Grandjean H, Vellas B: Body composition and osteoporosis in elderly women. Gerontology 2000, 46(4):189-193.

48. Baumgartner RN: Body composition in healthy aging. Ann N Y Acad SCl 2000, 904:437-448

49. Castaneda C, Bermudez Ol, Tucker KL: Protein nutritional status and function are associated with type 2 diabetes in Hispanic elders. Am J Clin Nutr 2000, 72(1):89-95. 
50. Gariballa S, Alessa A: Sarcopenia: prevalence and prognostic significance in hospitalized patients. Clin Nutr 2013, 32(5):772-776.

51. Rockwood K, Mitnitski A, Song X, Steen B, Skoog I: Long-term risks of death and institutionalization of elderly people in relation to deficit accumulation at age 70. J Am Geriatr Soc 2006, 54(6):975-979.

52. Bandeen-Roche K, Xue QL, Ferrucci L, Walston J, Guralnik JM, Chaves P, Zeger SL, Fried LP: Phenotype of frailty: characterization in the women's health and aging studies. J Gerontol A Biol Sci Med Sci 2006, 61(3):262-266.

53. Rothman MD, Leo-Summers L, Gill TM: Prognostic significance of potential frailty criteria. J Am Geriatr Soc 2008, 56(12):2211-2216

54. Wang SY, Shamliyan TA, Talley KM, Ramakrishnan R, Kane RL: Not just specific diseases: systematic review of the association of geriatric syndromes with hospitalization or nursing home admission. Arch Gerontol Geriatr 2013, 57(1):16-26.

55. Ray NF, Chan JK, Thamer M, Melton $\sqcup$ 3rd: Medical expenditures for the treatment of osteoporotic fractures in the United States in 1995: report from the National osteoporosis foundation. J Bone Miner Res 1997, 12(1):24-35.

56. Dodds R, Denison HJ, Ntani G, Cooper R, Cooper C, Sayer AA, Baird J: Birth weight and muscle strength: a systematic review and meta-analysis. J Nutr Health Aging 2012, 16(7):609-615.

57. Robinson SM, Simmonds SJ, Jameson KA, Syddall HE, Dennison EM, Cooper C, Sayer AA: Muscle strength in older community-dwelling men is related to type of milk feeding in infancy. J Gerontol A Biol Sci Med Sci 2012, 67(9):990-996.

58. Sayer AA, Robinson SM, Patel HP, Shavlakadze T, Cooper C, Grounds MD: New horizons in the pathogenesis, diagnosis and management of sarcopenia. Age Ageing 2013, 42(2):145-150.

59. White TA, Lebrasseur NK: Myostatin and sarcopenia: opportunities and challenges - a mini-review. Gerontology 2014, 60(4):289-293.

60. Morley JE, Von Haehling S, Anker SD: Are we closer to having drugs to treat muscle wasting disease? I Cachexia Sarcopenia Muscle 2014, 5(2):83-87.

doi:10.1186/2049-3258-72-45

Cite this article as: Beaudart et al: Sarcopenia: burden and challenges for public health. Archives of Public Health 2014 72:45.

\section{Submit your next manuscript to BioMed Central and take full advantage of:}

- Convenient online submission

- Thorough peer review

- No space constraints or color figure charges

- Immediate publication on acceptance

- Inclusion in PubMed, CAS, Scopus and Google Scholar

- Research which is freely available for redistribution 